\title{
Interfacial Microstructure and Mechanical Properties of Fluxless Arc Brazing of Aluminum Alloy to Steel with the Aid of Milling
}

\author{
Wei Cong ${ }^{1}$, Huibin $\mathrm{Xu}^{1,2, *}$, Yongqiang Deng ${ }^{1}$, Pengyu Gao ${ }^{1}$, Song Tang ${ }^{1}$, Pan $\operatorname{Tan}^{1}$ and Xiaxia Chen ${ }^{1}$ \\ ${ }^{1}$ College of Material Science and Engineering, Chongqing University of Technology, Chongqing 400054, China \\ ${ }^{2}$ State Key Laboratory of Advanced Welding and Joining, Harbin Institute of Technology, Harbin 150001, China
}

\begin{abstract}
Fluxless arc brazing technique using $\mathrm{Zn} 15 \% \mathrm{Al}$ filler wire with the aid of an additional milling procedure was developed to join aluminum alloy to low-carbon steel. It was found that the addition of a milling procedure during arc brazing could significantly change morphology and distribution of interfacial reaction products of the joint. By adjusting the radial cutting depth $\left(\mathrm{a}_{\mathrm{e}}\right)$, the original continuous layer-wised $\mathrm{Fe}-\mathrm{Al}$ intermetallic compounds (IMC) was broken into discrete IMC layer. The IMC layer was identified to be $\theta$-FeAl $\mathrm{I}_{3}$ with thickness ranging from $2.5 \mu \mathrm{m}$ to $14.4 \mu \mathrm{m}$ under optimized $\mathrm{a}_{\mathrm{e}}$ of $0.10 \mathrm{~mm}$. Upon shear loading, the maximum average interfacial shear strength reaches $182 \mathrm{MPa}$ and the crack propagated through both the steel/braze interface and remaining $\mathrm{Zn}-\mathrm{Al}$ filler alloy, which is highly favorable in crack deflection and in turn, improving bonding strength. It is thus concluded that milling assisted arc brazing is of great potential to achieve strong bonding between dissimilar Al alloy and steel. [doi:10.2320/matertrans.MT-M2020307]
\end{abstract}

(Received September 24, 2020; Accepted March 11, 2021; Published June 4, 2021)

Keywords: dissimilar metal joint, radial cutting depth, interfacial reaction, intermetallic compound, the fracture behaviors

\section{Introduction}

There has been an increasing demand for aluminum/steel dissimilar metal connections in the industrial field, primarily for the sake of weight reducing and improved energy efficiency. ${ }^{1)}$ However, the joining of aluminum to steel is difficult due to significant mismatch in chemical/physical properties and poor metallurgical compatibility of $\mathrm{Al} / \mathrm{Fe}$ system. ${ }^{2)}$ When conventional welding techniques were employed to weld $\mathrm{Al}$ to steel, a large population of $\mathrm{Al}-\mathrm{Fe}$ IMC would form at the joint interface. These IMCs have been long recognized to be extremely brittle in nature, and exhibit considerable detrimental effect on bonding strength. ${ }^{3,4)}$ As a consequence, great efforts have been made, in an attempt to alleviate the undesirable interfacial IMC phases.

To solve this welding problem, fusion welding, arc brazing and stirring friction welding methods have also increasingly applied in the joining of aluminum to steel. During the process of fusion welding, residual stress easily formed under a high thermal cycle, which caused the formation of crack at joint interface. ${ }^{5,6}$ In addition, excessive growth of intermetallic compounds causes their thickness to increase, which hindering the improvement of joint mechanical properties. Because of its advantages on proper energy output, high heating or cooling rate and flexibility, arc-brazing technologies offers a great potential for the $\mathrm{Al} / \mathrm{Fe}$ joining. ${ }^{7-11)}$ Owing to considerably reduced heat input compared with conventional fusion welding, the thickness of interfacial IMCs can be greatly restricted $(\sim 10 \mu \mathrm{m})$, thus improved joint strength can be anticipated. ${ }^{12)}$ However, despite of the improvement in bonding strength, the success in arc welding-brazing of $\mathrm{Al}$ alloy and steel remains limited. Because the layer-wised IMCs distributing parallel with bonding interface still play role of rapid crack propagation route upon mechanical loading, leading to premature failure and poor structural integrity of the joint. Friction stir welding is a solid phase

*Corresponding author, E-mail: hbxu@cqut.edu.cn welding method that can achieve low temperature welding and obtain more curved joint interface morphology, which is conducive to the improvement of joint strength. ${ }^{13-16)}$ However, the insufficiently metallurgical reaction at a low joining temperature can lead to formation of some defects. The base material particles peeled off by the stirring tool do not fully react in the weld clock, so it is easy to form the source of cracks. ${ }^{17)}$ Therefore, one may expect that further improvement in bonding strength of $\mathrm{Al} /$ steel joint can be obtained if the advantages of both welding-brazing and stir welding can be synergistically exploited. In one of our previous preliminary investigation, attempt has already been made to achieve this goal by arc brazing Al alloy to 304 stainless steel with the aid of an additional milling procedure. ${ }^{18)}$ It was preliminary revealed that robust $\mathrm{Al} /$ steel butt joints with wavy interface can be achieved by arc brazing with the aid of milling (ABM), and the thickness of IMC layer could be controlled as thin as $1.2 \mu \mathrm{m}$. A low melt point $\mathrm{Zn}-\mathrm{Al}$ filler metal can lead to decreasing on bonding temperature, which can avoid to growing excessively thick IMC layer at the joint interface. In addition, zinc element can change the type of $\mathrm{Fe}-\mathrm{Al}$ intermetallic compounds and help improve the plasticity of the IMC layer. ${ }^{19)}$

To this end, Al/steel arc brazing joints were obtained successfully without flux. Current investigation was commissioned to further validate the feasibility of this ABM technique in enhancing strength of $\mathrm{Al} /$ steel joint via creating continuous and wavy IMC layer. The evolution process of the microstructure of brazed metal and joint interface near steel with a variation of $a_{e}$ were primarily studied. Besides, the fracture behaviors of joints interface were also emphatically investigated to indicate the influence of different $a_{e}$ on the interfacial shear properties.

\section{Experimental Materials and Method}

5052 aluminum alloy and Q235 steel, and the size of specimen was $60 \mathrm{~mm} \times 50 \mathrm{~mm} \times 3 \mathrm{~mm}$ were selected as 
Table 1 Chemical composition of base materials (mass\%).

\begin{tabular}{cccccccccccc}
\hline Alloys & $\mathrm{C}$ & $\mathrm{Si}$ & $\mathrm{Cu}$ & $\mathrm{Mg}$ & $\mathrm{Cr}$ & $\mathrm{Mn}$ & $\mathrm{Zn}$ & $\mathrm{S}$ & $\mathrm{P}$ & $\mathrm{Fe}$ & $\mathrm{Al}$ \\
\hline 5052 & - & 0.25 & 0.10 & $2.2 \sim 2.8$ & $0.15 \sim 0.35$ & 0.10 & 0.10 & - & - & 0.40 & Bal. \\
Q235 & $\leq 0.22$ & $\leq 0.35$ & - & - & - & $\leq 1.4$ & - & $\leq 0.05$ & $\leq 0.045$ & Bal. & - \\
\hline
\end{tabular}

Table 2 Chemical composition of $\mathrm{Zn} 15 \% \mathrm{Al}$ filler metal (mass\%).

\begin{tabular}{ccccc}
\hline Elements & $\mathrm{Al}$ & $\mathrm{Cu}$ & $\mathrm{Mg}$ & $\mathrm{Zn}$ \\
\hline $\mathrm{Zn15 \% \textrm {Al }}$ & 15 & 0.50 & 0.015 & Bal. \\
\hline
\end{tabular}

parent materials. The welding wires used in joining process were $\mathrm{Zn} 15 \% \mathrm{Al}$ welding wire with a diameter in $1.6 \mathrm{~mm}$. Their corresponding chemical compositions of base materials and filler metal as shown in Table 1 and Table 2, respectively.

The ABM welding technology equipment including TIG welder and milling platform is given in Fig. 1. In the horizontal plane, the distance between the Tungsten Electrode and milling cutters is about $10 \mathrm{~mm}$. Besides, the title angle of the tungsten electrode and welding wire in the

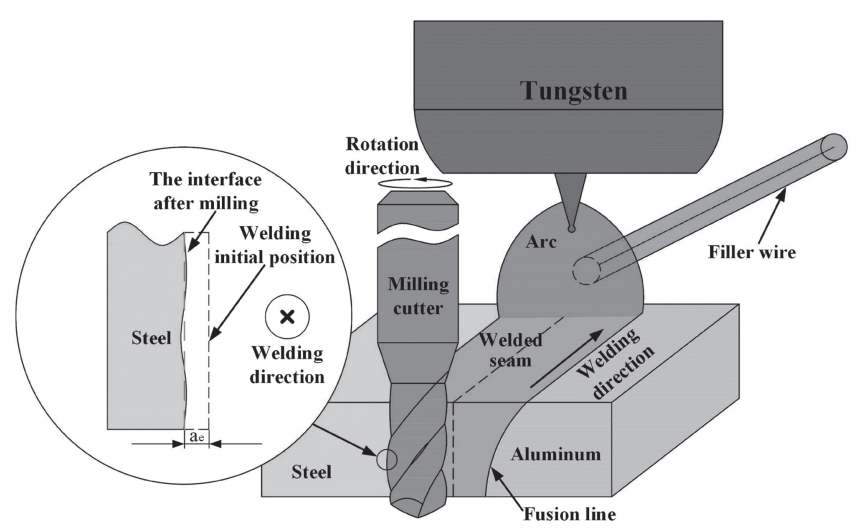

Fig. 1 Schematic of milling treatment at steel surface during ABM joining process. horizontal plane was $75^{\circ}$ and $15^{\circ}$, respectively. The buttwelded gap between two base metals was $2 \mathrm{~mm}$. The diameter of milling cutter used in the test was $2 \mathrm{~mm}$. The milling cutter has four spiral blades. As shown in Fig. 1, the ABM process of aluminum alloy to steel.

The following welding parameter was adopted: welding current (AC) was $70 \mathrm{~A}$, welding speed was $44 \mathrm{~mm} / \mathrm{min}$, rotation speed was $2720 \mathrm{r} / \mathrm{min}$, feeding speed of wires was $720 \mathrm{~mm} / \mathrm{min}$, and flow of argon was $10 \mathrm{~L} / \mathrm{min}$. In addition, $\mathrm{a}_{\mathrm{e}}$ changed from $0 \mathrm{~mm}$ to $0.18 \mathrm{~mm}$. Moreover, the milling cutter milling the steel matrix under counter-clockwise rotation conditions in the welding pool. It was noticed that the high-temperature liquid metal in the welding process consistently surrounded the milling cutter. After welding, the workpiece air - cooled cooler.

The Schematic of shear strength experiment was given in Fig. 2. As shown in Fig. 2(a), subsequent to remove the weld reinforcement, sub-sized specimens with the dimension of $3 \mathrm{~mm} \times 8 \mathrm{~mm} \times 20 \mathrm{~mm}$ were sectioned from the as-welded joint for shear test. To ensure the accuracy of the tests, at least three samples were tested under the same condition. Take the average value of the shear tensile as the final welding strength. And, the shear test speed was $2 \mathrm{~mm} / \mathrm{min}$ using WDW-E200 universal testing machine and put into a specific shear fixture as seen in Fig. 2(b). When testing the mechanical properties of the joint, the shear position was in the joint interface. After welding, the joint microstructure (a)

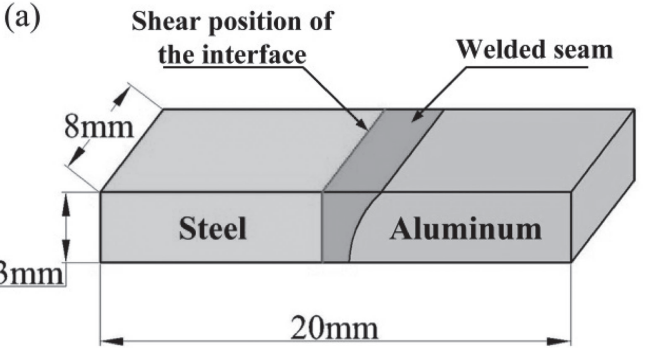

(b)

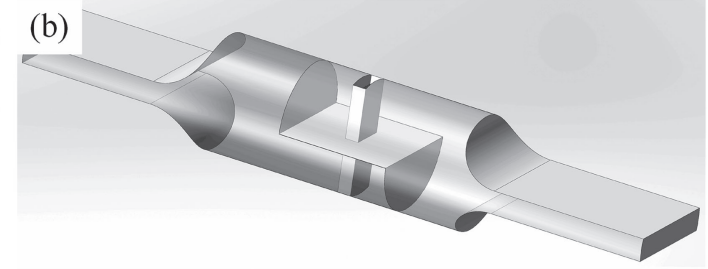

Fig. 2 Schematic of shear strength experiment (a) schematic diagram of shear specimen and (b) shear fixture of joint. 


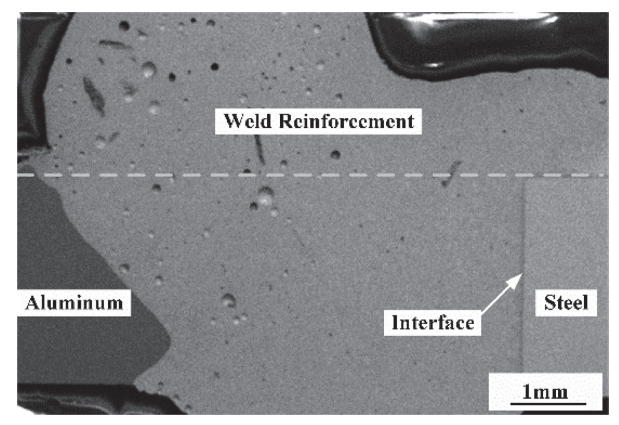

Fig. 3 Typical cross-section of the aluminum-steel joint.

was measured by scanning electron microscopy (SEM). The energy dispersive spectrometer (EDS) and the X-ray diffraction (XRD) were used to analyze the compositions of the joint fracture.

\section{Results and Discussion}

\subsection{Macrostructure of the aluminum-steel joint}

Figure 3 shows the typical cross-section of the aluminumsteel joint, the joint had the typical characteristics of arc brazing joints. With help of wetting action of $\mathrm{Zn}$ element, the fill metal can be spread fully on the steel surface after melting. With the aid of an additional milling procedure, the oxide film on the surface of the steel substrate is broken, and the fill metal quickly wet with the steel to form metallurgical bond. Ultimately, an obvious fusion line was on the aluminum alloy side, while the low carbon steel maintained solid characteristics and reacted with liquid metal to form an interface.

\subsection{Microstructures and intermetallic}

Figure 4(a) shows the interface of the joint welded at $\mathrm{a}_{\mathrm{e}}$ of $0 \mathrm{~mm}$. It can be clearly seen that a relatively homogeneous IMC layer with the maximum thickness about $16.5 \mu \mathrm{m}$ was generated at the joint interface. In addition, a continuous void zone along interface was observed. According to the compositions at point 1 shown in Fig. 4(a) and Al-Fe phase diagram, ${ }^{20)}$ the type of IMCs at point 1 was $\theta-\mathrm{FeAl}_{3}$ phase. Besides, since $\mathrm{Zn}-\mathrm{Al}$ filler metal was used in this experiment, zinc element was also examined at point 1 . This is because the $\mathrm{Zn}$ atom can enter the vacancy of $\theta-\mathrm{FeAl}_{3}$, thus forming a new ternary phase $\mathrm{FeAl}_{3} \mathrm{Zn}_{\mathrm{x}}$, which has the same crystal structure with $\theta-\mathrm{FeAl}_{3}$ phase. ${ }^{21)}$ In short, the joint interface was mainly composed of a straight $\theta-\mathrm{FeAl}_{3}$ layer with a thickness about $16.5 \mu \mathrm{m}$, which would affect the shear strength.

Seen from Fig. 4(b), there is a noticeable change on the microstructure of joint interface comparison with one in Fig. 4(a). In this case, a curved joint interface was observed, where a continuous and wavy-shape IMC layer was distributed. Moreover, according to the Fe-Al binary phase diagram and compositions in micro-zone 2 in Fig. 4(b), the IMC layer was mainly composed of $\mathrm{FeAl}_{3}-\mathrm{Znx}$ phase. The maximum width and minimum one of IMC layer was about $14.4 \mu \mathrm{m}$ and $2.5 \mu \mathrm{m}$, respectively. When $\mathrm{a}_{\mathrm{e}}$ was $0.1 \mathrm{~mm}$, the thickness of IMC layer significantly changed. As shown in Fig. 4(b), some IMC fragments broken by the milling cutter were scattered near the interface, which disrupted from the IMC layer during joining process of ABM. When $a_{e}$ was $0.1 \mathrm{~mm}$, the wavy-shaped interfacial structure was obtained, and the mechanical bonding of microinterlock was achieved. $^{22)}$

As shown in Fig. 4(c), the joint interface was more curved and some voids appeared along the interface. The IMC layer was divided into two layers, of which Continuous wavyshaped IMC layer with approximately thickness of $17.4 \mu \mathrm{m}$ and $11.9 \mu \mathrm{m}$ were observed. In hence, the total thickness of the IMC layer was about $29.3 \mu \mathrm{m}$. Based on EDS result, the phase marked by II and I in Fig. 4(c) was composed of $\theta-\mathrm{FeAl}_{3}$ and $\eta-\mathrm{Fe}_{2} \mathrm{Al}_{5}$ phase, respectively. The changes on the interfacial microstructure should be related to the large number of steel chips segregated near steel. In detail, the diffusion of $\mathrm{Al}$ atom to $\eta-\mathrm{Fe}_{2} \mathrm{Al}_{5}$ phase formed on steel
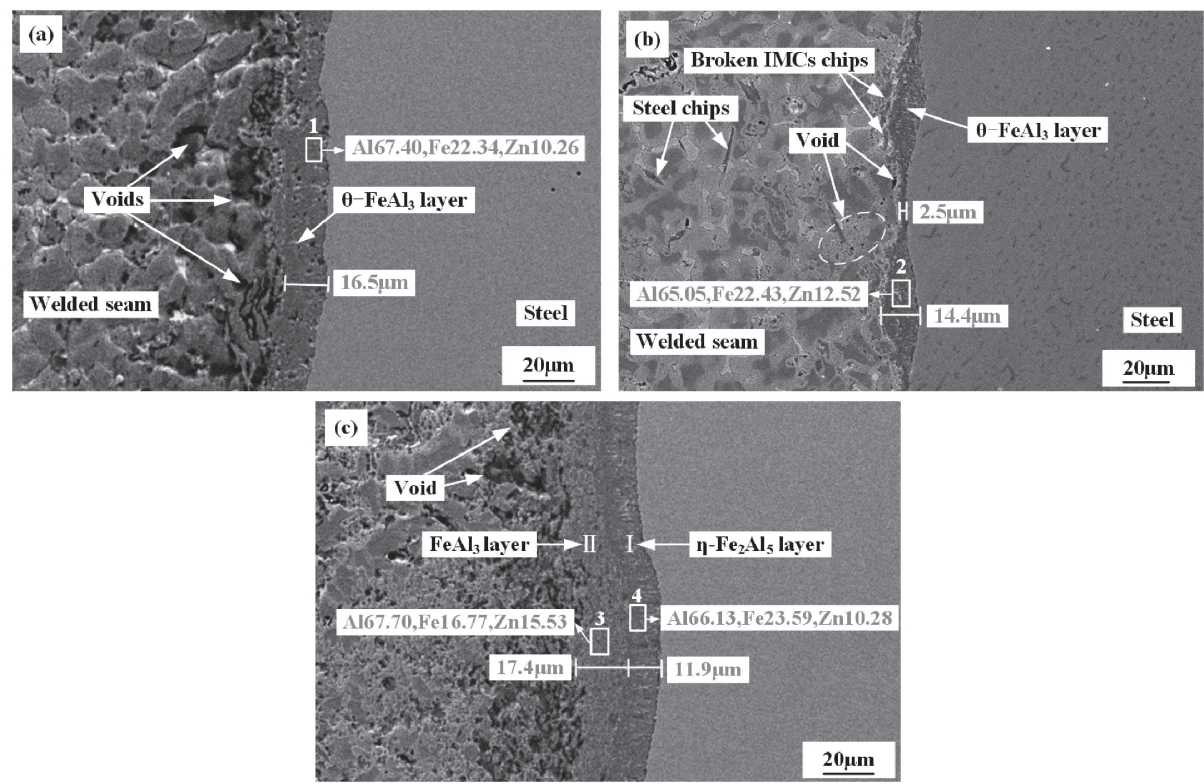

Fig. 4 The microstructure of joint interface at different $\mathrm{a}_{\mathrm{e}}$ (a) $0 \mathrm{~mm}$, (b) $0.1 \mathrm{~mm}$ and (c) $0.18 \mathrm{~mm}$. 
substrate was obviously hindered by the poor liquidity of the filler metal. Therefore, when $\mathrm{a}_{\mathrm{e}}$ up to $0.18 \mathrm{~mm}, \eta$ - $\mathrm{Fe}_{2} \mathrm{Al}_{5}$ phase was preferentially formed, Iron atom diffused to the liquid aluminum through IMCs and reacted with the liquid aluminum to form $\mathrm{FeAl}_{3}$ phase. During the solid-liquid interface reaction, the interfacial compounds dissolved and regenerated simultaneously, and the growth rate of the non-formed interfacial compounds is much lower than the dissolution rate of the interfacial reaction products. ${ }^{23)}$ In short, with the further increasing on $\mathrm{a}_{\mathrm{e}}$, a large number of voids and thicker IMC layer were easy to form near interface, which would reduce the interfacial shear strength.

As shown in Fig. 5, the effect of $\mathrm{a}_{\mathrm{e}}$ on the shear strength of the interface. With the increasing on $a_{e}$, the shear strength gradually increased first, and then sharply decreased. Only when $\mathrm{a}_{\mathrm{e}}$ was $0.1 \mathrm{~mm}$, the joint had the highest shear strength among these three joints. This demonstrated that an ideal joint interface with continuous and wavy-shape IMC layer should be responsible for this.

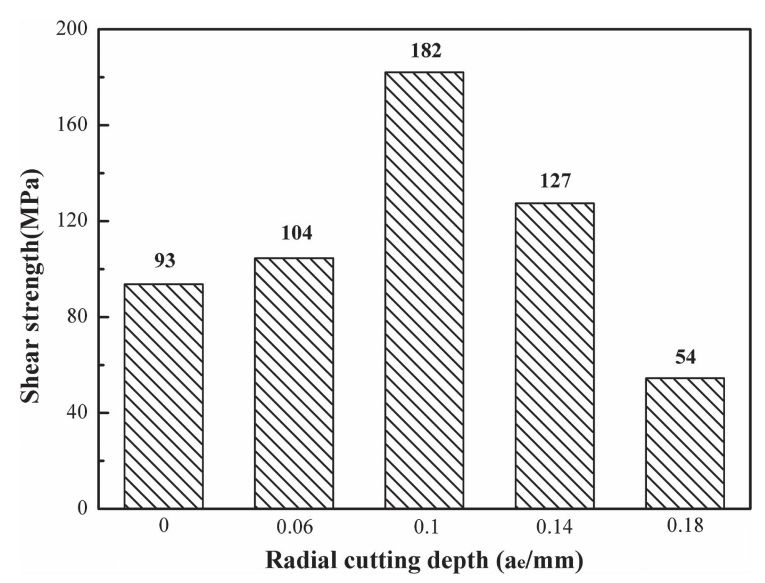

Fig. 5 Shear strength of joint interface at a various $a_{\mathrm{e}}$.

\subsection{Fracture behaviors of the joint interface}

Figures 6-9 show the fracture modes of the joints at different $a_{e}$. When $a_{e}$ was $0.1 \mathrm{~mm}$, the optimum joint shear strength (the shear strength was $182 \mathrm{MPa}$ ) was obtained. This indicates that continuous and wave-shaped IMC layer were beneficial to enhance the interfacial shear strength.

The fracture modes of the joint $\left(a_{\mathrm{e}}\right.$ was $\left.0 \mathrm{~mm}\right)$ given in Fig. 6. For $\mathrm{a}_{\mathrm{e}}$ was $0 \mathrm{~mm}$, the interfacial shear strength was $93 \mathrm{MPa}$, and the macroscopic interface of the joint was relatively straight. In magnified SEM images of point $\mathrm{A}$ in Fig. 6(b), there were found a thin IMC layer (marked as point A) was identified as $\mathrm{FeAl}_{3}$ phase. The phase marked by II in fracture surface was $\mathrm{FeAl}_{3}$ phase according to the EDS results listed in Table 3. XRD results on the fracture surface shown in Fig. 6(d), this indicates that the fracture surface was composed of $\mathrm{Zn}$, iron and $\theta-\mathrm{FeAl}_{3}$ phase. The EDS identification results of the fractured surface were consistent with the quantitative results confirmed by XRD. As stated above, this reveals that the fracture was occurred along the interface between IMC layer and steel substrate. According to the results of fracture surface observation, the schematic diagram of fracture path of joint given in Fig. 9(a).

For $a_{e}$ of $0.1 \mathrm{~mm}$, the interfacial shear strength of the joint was $182 \mathrm{MPa}$. The fracture modes of the joints $\left(\mathrm{a}_{\mathrm{e}}\right.$ was $0.1 \mathrm{~mm}$ ) shown in Fig. 7. As shown by Fig. 7(b), there are still IMCs on the steel substrate. After EDS analysis listed in Table 4, it can be determined that the point B, I, II, III was identified as $\theta-\mathrm{FeAl}_{3}$ phase, Iron, $\theta-\mathrm{Fe} \mathrm{Al}_{3}$ phase, filler metal, respectively. Moreover, it can be seen that the steel substrate was exposed at the interface of the fracture surface. According to XRD results shown in Fig. 7(d), this inferred that $\mathrm{Zn}$, iron and $\theta-\mathrm{FeAl}_{3}$ phase was existed on fractured surface. The EDS identified results of the fracture surface agree with quantitative one confirmed by XRD. As stated above, this reveals that the fracture path mainly occurred among IMC layer, filler metal and steel base metal. When $a_{e}$
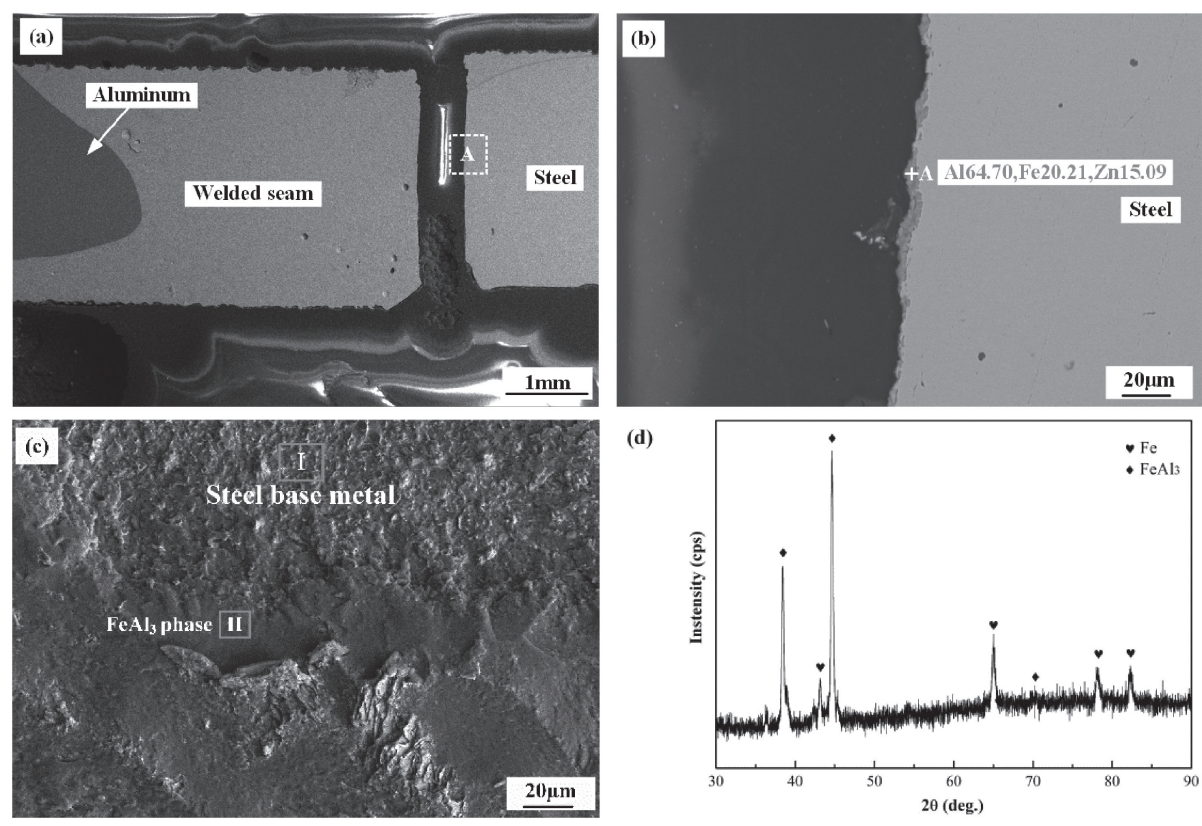

Fig. 6 The fracture modes of the joint ( $a_{e}$ was $0 \mathrm{~mm}$ ) (a) Macro-fracture profile of the joint, (b) Magnified SEM images of the joint in region $\mathrm{A}$ by squares in (a), (c) fracture surface and (d) XRD results of the steel fracture surface. 

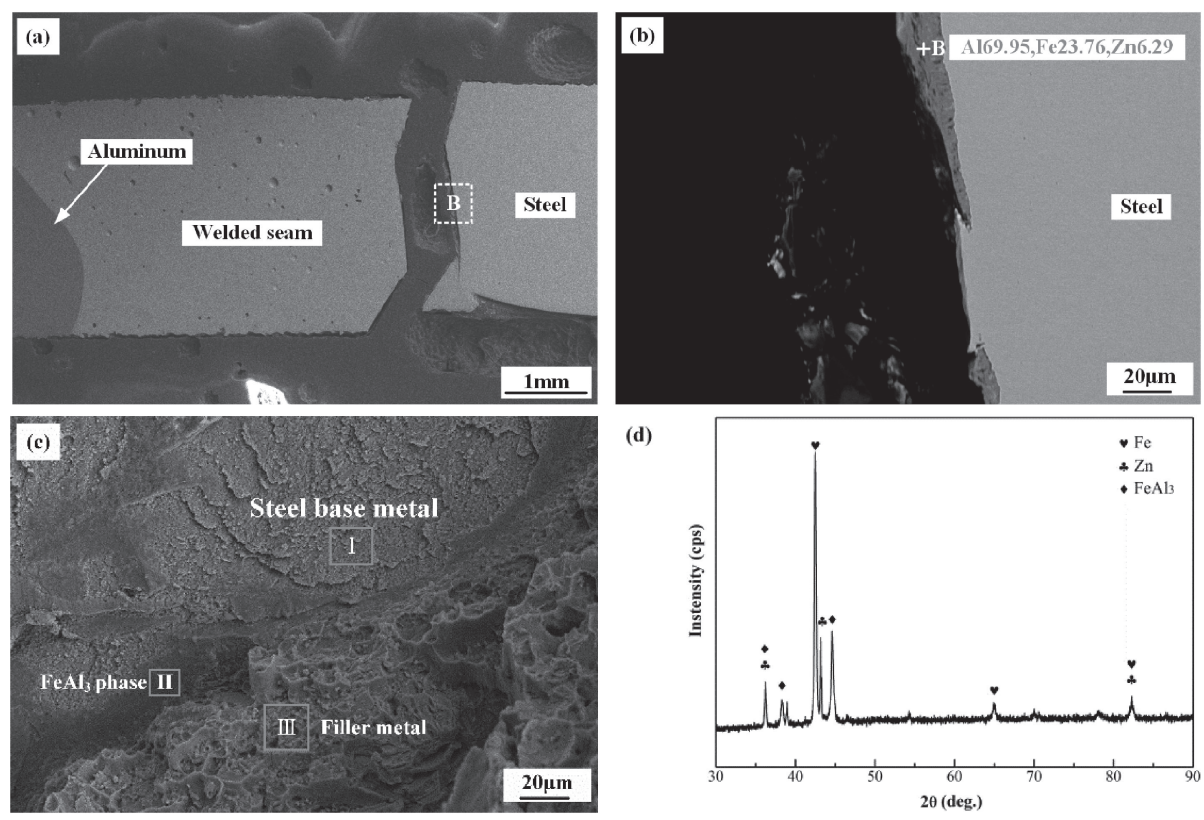

(d)

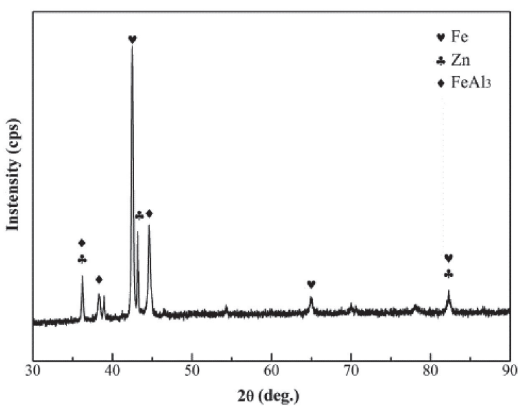

Fig. 7 The fracture modes of the joint ( $a_{e}$ was $0.10 \mathrm{~mm}$ ) (a) Macro-fracture profile of the joint, (b) Magnified SEM images of the joint in region B by squares in (a), (c) fracture surface and (d) XRD results of the steel fracture surface.
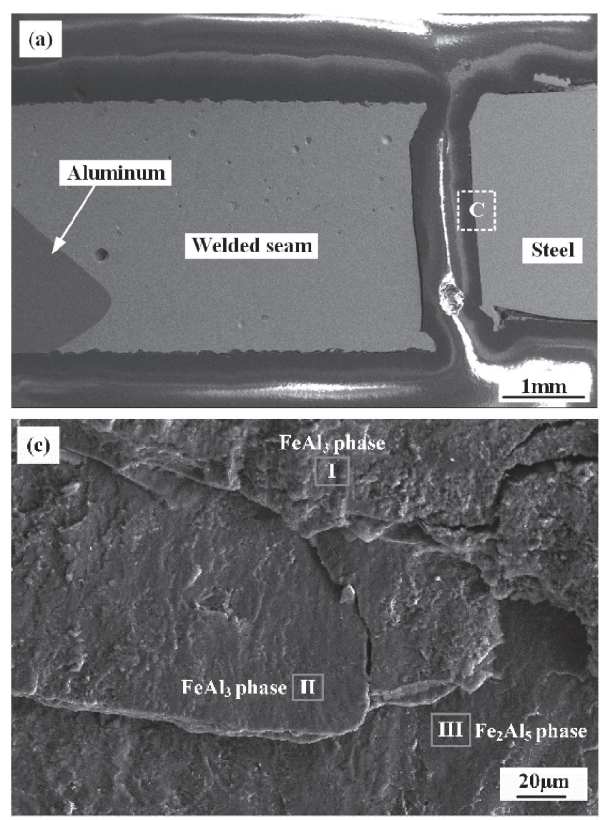

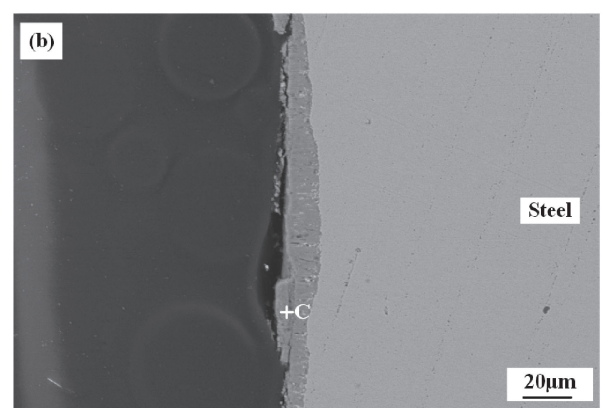

(d)

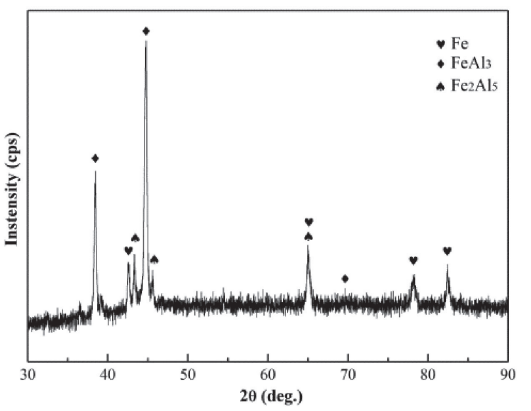

Fig. 8 The fracture modes of the joint ( $a_{\mathrm{e}}$ was $0.18 \mathrm{~mm}$ ) (a) Macro-fracture profile of the joint, (b) Magnified SEM images of the joint in region $\mathrm{C}$ by squares in (a), (c) fracture surface and (d) XRD results of the steel fracture surface.

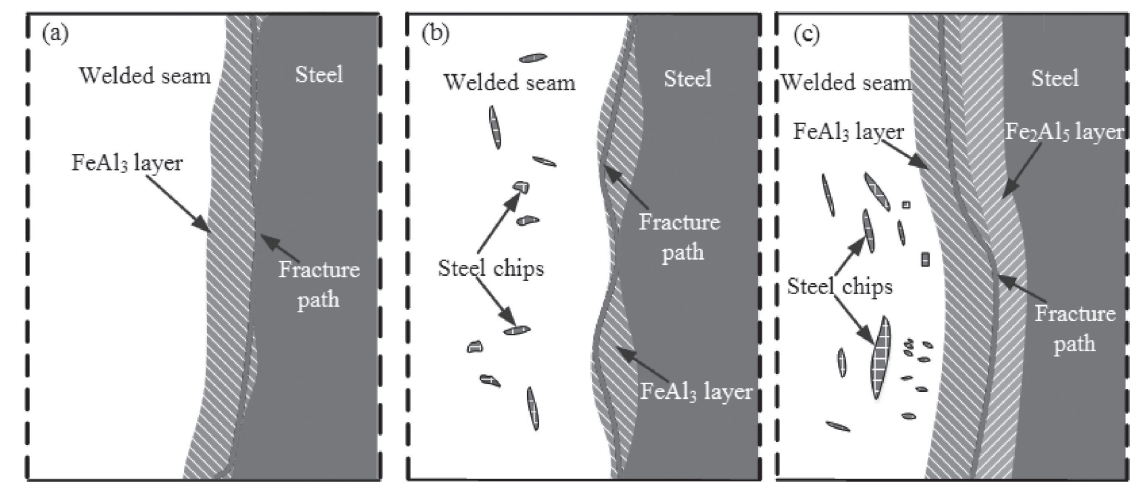

Fig. 9 The schematic diagram of fracture path at different $\mathrm{a}_{\mathrm{e}}$ (a) $0 \mathrm{~mm}$, (b) $0.1 \mathrm{~mm}$ and (c) $0.18 \mathrm{~mm}$. 
Table 3 EDS results of zones I-II in Fig. 6.

\begin{tabular}{ccccc}
\hline Test zone & Fe (at.\%) & Al (at.\%) & Zn (at.\%) & Phases \\
\hline A & 20.21 & 64.70 & 15.09 & $\mathrm{FeAl}_{3}$ \\
I & 94.16 & 4.73 & 1.11 & Iron \\
II & 23.51 & 69.80 & 6.69 & $\mathrm{FeAl}_{3}$ \\
\hline
\end{tabular}

Table 4 EDS results of zones I-III in Fig. 7.

\begin{tabular}{ccccc}
\hline Test zone & Fe (at.\%) & Al (at.\%) & Zn (at.\%) & Phases \\
\hline B & 23.76 & 69.95 & 6.29 & $\mathrm{FeAl}_{3}$ \\
I & 95.57 & 1.40 & 3.03 & Iron \\
II & 22.71 & 70.56 & 6.73 & $\mathrm{FeAl}_{3}$ \\
III & 8.73 & 50.12 & 41.14 & Zn-Al alloy \\
\hline
\end{tabular}

Table 5 EDS results of zones I-III in Fig. 8.

\begin{tabular}{ccccc}
\hline Test zone & Fe (at.\%) & Al (at.\%) & Zn (at.\%) & Phases \\
\hline C & 27.77 & 67.16 & 5.07 & $\mathrm{Fe}_{2} \mathrm{Al}_{5}$ \\
I & 16.3 & 58.83 & 24.87 & $\mathrm{FeAl}_{3}$ \\
II & 23.58 & 71.43 & 4.99 & $\mathrm{FeAl}_{3}$ \\
III & 27.68 & 66.21 & 6.10 & $\mathrm{Fe}_{2} \mathrm{Al}_{5}$ \\
\hline
\end{tabular}

was $0.1 \mathrm{~mm}$, the shear strength of joint interface reached the maximum value of $182 \mathrm{MPa}$ among these three joints. In this case, the thickness of IMC was reduced, and distributed in a wavy-shaped. Usually, in the term of friction stir welding and explosion welding of aluminum to steel, the characteristics of microinterlock can hinder the propagation of crack. ${ }^{24,25)}$ Therefore, the microinterlock and wavy-shaped interfacial structure would be beneficial to increase the joint mechanical strength. According to the results of fracture surface observation, the schematic diagram of fracture path of joint as shown in Fig. 9(b).

For $\mathrm{a}_{\mathrm{e}}$ of $0.18 \mathrm{~mm}$, the interfacial shear strength of the joint is $54 \mathrm{MPa}$. Macro-fracture profile and magnified SEM images of the joint given in Fig. 8(a) and (b). The phase marked by point $\mathrm{C}$ in Fig. 8(b) was identified as $\eta-\mathrm{Fe}_{2} \mathrm{Al}_{5}$ phase according to the EDS results. As seen in Fig. 4(c) and Fig. 8(b) shown, it can be preliminary deduced that the fracture occurred between $\mathrm{Fe}_{2} \mathrm{Al}_{5}$ and $\mathrm{FeAl}_{3}$ layer. The fracture surface consisted of lamellar structure phase shown in Fig. 8(c) was observed. The steel base metal (marked as I), and $\mathrm{FeAl}_{3}$ phase (marked as II) and filler metal (marked as III) was identified according to the EDS results listed in Table 5, respectively. XRD result of the fracture surface in steel side as shown in Fig. 8(d). It confirms that the fractured surface was composed of $\mathrm{Zn}$, iron, $\eta-\mathrm{Fe}_{2} \mathrm{Al}_{5}$ phase and $\theta$ $\mathrm{FeAl}_{3}$ phase. As stated above, this further indicated that the fracture path was not only mainly occurred in the interface between $\eta$ - $\mathrm{Fe}_{2} \mathrm{Al}_{5}$ layer and $\theta-\mathrm{FeAl}_{3}$ layer, but also existed 
inside $\theta-\mathrm{FeAl}_{3}$ layer. According to the results of fracture surface observation, the schematic diagram of fracture path of joint given in Fig. 9(c). Compared with the best strength joints $\left(\mathrm{a}_{\mathrm{e}}\right.$ was $\left.0.1 \mathrm{~mm}\right)$, the shear strength of this joint was decreased. This decreased in shear strength was associated with excessive IMC layer thickness $(>10 \mu \mathrm{m}) .{ }^{26)}$ Therefore, a medium $\mathrm{a}_{\mathrm{e}}$ was important for a sounder joint.

\section{Conclusions}

(1) Dissimilar metals between Q235 steel and 5052 aluminum alloy were butt jointed successfully by arc brazing using $\mathrm{Zn} 15 \% \mathrm{Al}$ filler wire with the aid of an additional milling procedure. The $\mathrm{Al} /$ steel joints can be obtained without the use of flux.

(2) Homogeneous IMC layer was observed in joints made of $\mathrm{a}_{\mathrm{e}}$ was $0 \mathrm{~mm}$ or $0.18 \mathrm{~mm}$. The continuous wavyshaped IMC layer was obtained in joint made of moderate $\mathrm{a}_{\mathrm{e}}(0.10 \mathrm{~mm})$, of which the IMC thickness ranging from $2.5 \mu \mathrm{m}$ to $14.4 \mu \mathrm{m}$.

(3) Under optimized $a_{e}$ of $0.1 \mathrm{~mm}$, joint with wavy interface composed of discrete $\theta-\mathrm{FeAl}_{3} \mathrm{IMC}$ can be obtained.

(4) When $a_{e}$ was $0.1 \mathrm{~mm}$, the joint has the optimum mechanical properties of $182 \mathrm{MPa}$, owe to the continuous wavy-shaped IMC layer along the joint interface. Fracture path propagated by a fluctuating way with a high resistance for propagation of crack, which would increase the shear properties.

\section{Acknowledgements}

This work was financially supported by Basic Research and Frontier exploration project of Chongqing (the Natural Science Foundation of Chongqing) (No. cstc2018jcyjAX0705), The State Key Laboratory of Advanced Welding and Joining of China (No. AWJ-Z16-02), University Innovation Research Group of Chongqing (No. CXQT20023), Chongqing Talent Plan: Leading Talents in Innovation and Entrepreneurship (No. CQYC201903051) and graduate Student Innovation Program of Chongqing University of Technology (No. ycx20192038).

\section{REFERENCES}

1) J. Hirsch: Mater. Trans. 52 (2011) 818-824.

2) M.M. Atabaki, M. Nikodinovski, P. Chenier, J. Ma, M. Harooni and R. Kovacevic: J. Manuf. Sci. Prod. 14 (2014) 59-78.

3) E.H. Kim, K. Nakata and K.H. Song: Mater. Trans. 57 (2016) 686-690

4) H. Springer, A. Kostka, E.J. Payton, D. Raabe, A. Kaysser-pyzalla and G. Eggeler: Acta Mater. 59 (2011) 1586-1600.

5) S.B. Jamaludin, M.M. Noor, S.K.A. Kadir and K.R. Ahmad: Adv. Mater. Res. 795 (2013) 74-77.

6) R. Borrisutthekul, T. Yachi, Y. Miyashita and Y. Mutoh: Mater. Sci. Eng. A 467 (2007) 108-113.

7) J.L. Song, S.B. Lin, C.L. Yang, C.L. Fan and G.C. Ma: Sci. Technol. Weld. Joining 15 (2010) 213-218.

8) H. He, C. Wu, S. Lin and C. Yang: J. Mater. Eng. Perform. 28 (2019) 1180-1189.

9) H. Ma, G. Qin, X. Bai, L. Wang and Z. Liang: Int. J. Adv. Manuf. Technol. 86 (2016) 3135-3143.

10) K.P. Yagati, R. Bathe and J. Joardar: Trans. Indian Inst. Met. 72 (2019) 2763-2772.

11) M. Pouranvari and M. Abbasi: J. Alloy. Compd. 749 (2018) 121-127.

12) X. Yu, D. Fan, J. Huang and Y. Kang: Mater. Res. Express 6 (2019) 096533.

13) M. Pourali, A. Abdollah-zadeh, T. Saeid and F. Kargar: J. Alloy. Compd. 715 (2017) 1-8.

14) T. DebRoy and H.K.D.H. Bhadeshia: Sci. Technol. Weld. Joining 15 (2010) 266-270.

15) H. Uzun, C. Dalle, A. Argagnotto, T. Ghidini and C. Gambaro: Mater. Des. 26 (2005) 41-46.

16) C. Leitao, E. Arruti, E. Aldanondo and D.M. Rodrigues: Mater. Des. 106 (2016) 153-160

17) M.F.X. Muthu and V. Jayabalan: J. Mater. Process. Technol. 217 (2015) 105-113.

18) H. Xu, P. Gao, W. Cong, M. Li and Y. Cai: Mater. Sci. Technol. 35 (2019) 107-115.

19) H. Dong, W. Hu, Y. Duan, X. Wang and C. Dong: J. Mater. Process. Technol. 212 (2012) 458-464.

20) A.O. Mekhrabov and M.V. Akdeniz: Acta Mater. 47 (1999) 20672075.

21) H. Springer, A. Szczepaniak and D. Raabe: Acta Mater. 96 (2015) 203211.

22) K. Kimapong and T. Watanabe: Mater. Trans. 46 (2005) 835-841.

23) W. Song, K. Saida, A. Ando and K. Nishimoto: Q. J. Jpn. Weld. Soc. 22 (2004) 315-322.

24) J.T. Xiong, J.L. Li, J.W. Qian, F.S. Zhang and W.D. Huang: Sci. Technol. Weld. Joining 17 (2012) 196-201.

25) G.H.S.F.L. Carvalho, I. Galvão, R. Mendes, R.M. Leal and A. Loureiro: J. Mater. Process. Technol. 283 (2020) 116707.

26) J.L. Song, S.B. Lin, C.L. Yang and C.L. Fan: J. Alloy. Compd. 488 (2009) 217-222. 